This work aims to articulate insights between image and sound from the movie The Cook, the Thief, his Wife and her Lover (1989) from British director Peter Greenaway, investigating the performance from a poetic angle.

Key words: Peter Greenway, narrativity, music, cinema. 


\section{Imagens do pensamento sobre o ritmo no cinema}

Clelia

MELLO

Este trabalho busca articular algumas reflexões entre imagem e som presentes no filme O Cozinheiro, o Ladro, sua Mulher e seu Amante (1989) do diretor britânico Peter Greenaway, investigando a encenação sob um prisma poético.

Palavras-chave: cinema, Peter Greenaway, música, narratividade. 
O cinema, considerado uma arte do movimento que se desenrola temporalmente, possui um material característico de expressão que é configurado na articulação e na relação entre som e imagem, ou mais especificamente entre a tessitura sonora e a imagética. As variações, dependentes de sua duração, podem ser intermitentemente usadas para representar o processo mental e o mundo externo estabelecendo o ritmo. Esse movimento compassado se manifesta tanto nas funções vitais quanto nas ações usuais, como ordem e proporção no espaço e no tempo, e tem a capacidade de se tornar imperceptível tal qual o movimento dos astros ou a própria pulsação. Foi essa sutileza do ritmo junto à recorrente heterogeneidade dos elementos fílmicos que levou teóricos como Adorno e Eisler a sinalizar o caráter prosaico do cinema (organizado em função da narração direta de uma história) em contradição com as repetições e as relações de simetria características das formas poética e musical.

Mas também existe um cinema que superpõe ao imediatismo da prosa à organização formal de um conjunto de recursos expressivos, utilizando os elementos em que os conteúdos se manifestam também por suas propriedades materiais e formais específicas. Esse é o caso do cinema proposto por Peter Greenaway que desde os anos 70 vem explorando o uso da linguagem cinematográfica por meio da confluência entre formas artísticas e disciplinas culturais. Seus experimentos com os sistemas numéricos, as seqüências alfabéticas, os códigos de cores e tantos outros, são empreendimentos com a meta de deslocar a crença aparentemente inquestionável de que a narrativa é necessária e essencial para o cinema.

Para focalizar certos aspectos diferenciais de um proceder poético que não se enquadra a uma leitura cartesiana, a opção foi por passagens intervalares do filme The Cook, the Thief, his Wife and her Lover (1989); pois, além do sentido operístico na relação entre as artes, na tensão criada entre música e cinema, é aparentemente o de narrativa mais linear dentre as suas obras, devido a estrutura que parodia a dramática tradicional através de uma tragédia de vingança.

A ênfase à teatralidade é dada já no início: ao som em pri- 
meiro plano, denso, repetitivo e marcante, mistura-se os dos latidos de uma matilha ao fundo, sinalizando a entrada em cena - frente aos créditos e à claustrofóbica imagem de cães que, em plano tatame, farejam a meio corpo. As instâncias diferentes geram atenção ao sobrecarregar os sentidos, conservando-nos pouco à vontade. No movimento da câmera, com a mudança de perspectiva anunciando a saída dessa ação, a música se introduz como em continuidade. As indicações abrem-se em rede, preparando-nos para o jogo, com o deslocamento do olhar pela câmera que sobe a percorrer a estrutura dos andaimes.

$\mathrm{Na}$ figuralidade instaurada pela estrutura dos andaimes podemos considerar a questão do estabelecimento de um ponto de vista elevado, saindo do rés do chão, bem como a discussão sobre uma disputa, iniciada por nacos de carne. Além disso, lembra a função do prólogo no teatro, ou seja, quebrar a ilusão introduzindo o jogo teatral por patamares.

Na Grécia Antiga, o prólogo era a primeira parte da ação antes da primeira aparição do coro, que representava o senso comum. Mas o prólogo também podia ser recitado pelo coro que, por meio desse artifício retórico, resumia o enredo e a moral da peça. O suspense não era um elemento importante no jogo teatral, já que a platéia, comumente, conhecia o argumento. O modelo elisabetano tal como todo o teatro renascentista, em suas diferenças, baseou-se nas tragédias gregas.

Nesse sentido, em ritornello, do andaime aos cães, podemos inferir nos latidos uma manifestação do coro - como uma oração paralela a introduzir um dos motivos que permeará o filme: o canibalismo cultural. Um procedimento que com uma carga de impacto crescente desestrutura o próprio nexo causal.

A sensação visual e a auditiva se enriquecem em graus diferentes por não estarem moduladas espacialmente, intensificando mais e mais o jogo teatral. A não modulação entre o ponto de vista e o da escuta é uma das características que permeará todo o filme, predispondo o espectador a atentar. Diferentes conexões afloram, os sons crescem, diminuem, se esvanecem, pontuam a situação narrativa e a lógica interna modifica-se continuamente no jorro sônico e imagético.

A abertura, similarmente à operística, situa a audiência em 
relação ao discurso que se inicia. Provocando à atenção através da cadência, ambientação e enfoque, por entre a apresentação do tema musical que domina a mise en film, servindo como uma espécie de transição para o universo particular da cena. Abrem-se as cortinas apresentando, como ribalta, a soturna reconstrução estilizada de um estacionamento em um beco azulado, como que pelos luminosos em néon. Adentramos o corpo fílmico através de uma fábula de Peter Greenaway que, com sua moral sarcástica, foi inspirada em Tis Pity Shes a Whore, de John Ford. O procedimento dramático do teatro do renascimento inglês com o drama jacobeano, mantém as qualidades advindas do teatro elisabetano, sendo reutilizado em termos cinematográficos em total decalagem com o verismo e o neo-impressionismo do cinema dominante. A rede de correlações produz relações diferenciais.

O título referencialista que enquadra as personagens (o Cozinheiro, o Ladrão, sua Mulher e o Amante dela) - contém um embrião de ambigüidade narrativa ao explorar a extensão, bem como a própria grafia na abertura do filme. Por inferência também remete aos intertítulos antes do emprego da voz no cinema. E quando a voz se manifesta é gutural ressoando por entre os latidos, na grotesca e brutal cena que se passa no estacionamento, através das incisivas palavras de Spica - o ladrão - que, em exibição do orgânico, passa excremento na boca de um homem, Roy, ameaçando: "Abra a boca! Aprenda a apreciar o que come". Após o que urina em sua vítima complementando: "Quero comer e beber do melhor e custa caro". Uma verborragia que o acompanhará até o fim através de sua voracidade pantagruélica.

O filme é desconcertante, mórbido e violento. Com um estranho humor - british humour - que na derrisão da lógica e inversão da norma, intensifica o desconforto ao não permitir uma evasão fácil e efêmera. Através do jogo cênico, mostram-se aspectos convulsionados de um micro-cosmo que na lei da sobrevivência, do mais forte, vive segundo o maniqueísmo darwinista - comendo uns aos outros e/ou esquematizando subterfúgios. Na repetição desse tema, em sua rotação, ou de uma fração do mesmo (como imitação contrapontística), a frieza da 
sátira e o traço irônico atuam virulentamente como a forma deformante.

Quando o movimento se desloca à direita, como a observar o séquito a percorrer a fáustica cozinha, o som de uma voz em homilia chega antes sufocando o peso do maquinário cadenciado. Presença sonora transmutando a fragilidade da existência ao remeter a uma fase mais antiga da história individual por seu valor fantasmático. As sombrias palavras de contrição, retiradas do Salmo 51, manifestam-se como o sopro de um corpo, que em salmodia é, ironicamente, quem pede perdão por seus pecados: "elimine minhas transgressões, purga-me com hissopo e serei limpo, lava-me e serei mais claro que a neve".

No esconderijo onde se enterra o corpo advém enfim perceptível através de Pup - o angélico sopranino. Na expressão de uma coletividade em uma ação ritualística, o coro onipresente atua como uma voz interior: Miserere mei Deus, secundum magnam misericordiam tuam... A presença do canto aporta uma transcendência que livra do provincianismo do diálogo.

Pensando que nos primórdios da Igreja Cristã o serviço religioso consistia principalmente no cântico dos Salmos, além da presença dos mesmos em todas as bíblias, a pungente força da composição cria uma outra dimensão na adequação da transposição do ritual litúrgico à cena: ela é subseqüente a cruel humilhação da abertura e justamente a personagem que nos introduz ao espaço especializado do restaurante - a cozinha. Trata-se de uma antifonia, uma prece musical, realizada como um ato de contrição a serviço de uma ação em uma celebração específica. Emoldura-se assim a relação entre os vários espaços em jogo, ao mesmo tempo em que se salienta o aspecto ritualístico contido na encenação.

Nessa transferência para o espaço cavernoso da cozinha, conjuntamente igreja, sepulcro, masmorra, usina - que ecoa ressonante com a intensidade acústica de uma catedral - ao canto que alude ao culto religioso, contrapõe-se às imagens sombrias que contaminam o discurso musical: o ladrão, sua mulher e seu séquito entram em um cortejo arrastado e funesto como se adentrassem em um ambiente de calor infernal.

Analogamente a uma encenação musical pré-operística, os 
serviçais trabalham silenciosamente como se meditassem sobre as palavras ouvidas, envolvidos na preparação meticulosa dos alimentos. Na atitude quase religiosa intensificam o contraste. Uma referência que também pode ser feita à cozinha anterior a da nossa época, a do século XIX onde a voz do chef-patron ou de cuisine - o único com direito a palavra - soava para ser obedecida. Neste lugar, é o patron que se faz ouvir. Este equacionamento potencializa o conflito ao evidenciar o perfil da estrutura social através de seus antagonismos.

No jogo teatral os atores, colocados como signos para idéias, movem-se com um encadeamento extremamente coreográfico: conhecendo os parâmetros do espaço, seguram a opressão do alegórico, personificando significados advindos da tragédia elisabetana onde a violência, a paixão e a poesia eram inseparáveis. Como personagens vindas do teatro, fazem parte da cena entrando e saindo sem serem perseguidas pela câmera, por vezes com a marcação regida pelo cozinheiro. O intuito é o de nos fazer atentar à mise en film que não nos fornece uma percepção contínua, diluindo uma aproximação com sua implicação sentimental e desta forma nos tornar testemunhas atuantes, enfatizando o papel do espectador para além do de contemplativo.

A numerosa figuração, isolada em comportamento alheio, não interfere diretamente no desenrolar da ação. Com grandiosidade operística são apresentadas referências ao passado humanista. Molduras indutoras que são citações estilizadas imbricadas com o teatro, o cinema. Como na apresentação dos pratos a serem servidos com a introdução do tema musical Book Depository com o cozinheiro iluminando quadros vivos imobilizados por instantes.

Essas figuras saídas de outras telas para encarnar esse quadro, participam do nosso imaginário pictográfico. Elas são assentadas em diferentes modos de produção oriundas da sociedade capitalista em sua formação. Em polifonia sinalizam ao desenhar os corpos, por imposição da representação de si e do outro; sublinhando a intersecção entre a temporalidade do acontecimento dramático e a imobilidade da personagem.

Nos quadros justapostos a configuração é de um afresco. 
Na teatralidade a ênfase na representação de uma representação - o princípio da recursividade. A duplicação desse procedimento barroco criador de ilusão que parece abolir a fronteira entre o mundo do quadro pictural e o da audiência, materializa a moldura da tela, do cinema. Como câmeras de ressonância, com diferenciação e integração, essa densidade da tessitura domina a mise en film.

Nas situações que se desenvolvem através da passagem entre os espaços pertencentes ao restaurante, o imenso cenário subdivide-se em estações decoradas para cada episódio tal como nos mistérios medievais. E a mostração é conduzida de maneira linear lembrando o movimento dos olhos na leitura ocidental e a escrita musical segundo as regras do contraponto, cujo interesse se concentra na horizontalidade das linhas melódicas: do estacionamento à cozinha, à sala de jantar, aos banheiros e em direção oposta; por meio do código cromático dependente da iluminação que predomina no espaço: azul, verde, vermelho, branco...

Também através do princípio do palco-plataforma, com cenários simultâneos povoados de personagens alegóricas, evidencia-se que, como em um proscênio teatral, a quarta parede não existe e que estamos entre espaços: cênico, cinematográfico, pictural, arquitetônico, operístico. Em uma síntese que cria falsas perspectivas ao confundir nossas expectativas de proporção sonora e visual. E para exacerbar a artificialidade teatralizada a câmera é eqüidistante, evitando alinhar tempo e ponto de vista. Ao registrar as ações, as operações que se processam, é minimizada a sua ingerência, mantendo-se uma distância emocional ao permanecer retirada de envolvimento na ação com deliberada objetividade, com o quadro do cinema funcionando como um enquadramento cênico.

Esse procedimento, que tem a visão cenográfica baseada na simetria e no plano de conjunto, além de ressaltar a solidão acentua ainda mais a quebra da ilusão: na primeira seqüência, a do estacionamento, o carro do ladrão estaciona em cima da faixa dupla com os faróis acesos, de frente para a câmera. Quase que imediatamente há um giro da perspectiva da ação mostrando as personagens de costas para o restaurante - e para o 
público - e, conseqüentemente, a inversão do espaço da representação.

Embora a maioria dos espaços tenha um amplo plano longitudinal, para acentuar ainda mais o questionamento da representação de uma realidade, dotada de um sentido verdadeiro, o deslocamento da câmera e o enquadramento - com poucas exceções - são sempre de modo perpendicular ao ambiente onde a ação se desenvolve. Como na cena quando o ladrão e o cozinheiro estão na porta da cozinha e um personagem (Roy) desce o estacionamento em direção à mesma. Existe uma ortogonalidade que é diluída pela faixa pintada no chão, dando uma perspectiva um pouco diferente. Além disso, é realizada uma espécie de montagem em cena; bem como o reaproveitamento e deslocamento de certos objetos, cenários e a angulação da câmera. Nessa composição, por exemplo, o carro está posicionado para fazer um contraponto cromático acentuando a faixa dupla e a disposição espacial dos elementos postos em cena.

A iluminação teatral dificulta uma imersão no universo diegético, ao expressar o espaço - independentemente das personagens que o ocupam - intensifica o efeito do "desreal" para além do irreal, pois se trata de uma encenação. Em referência à pintura sublinha uma visibilidade, no jogo de luz e sombra, captada pela fotografia em movimento - a câmera cinematográfica. A intenção é desestabilizar as certezas em todos os espaços através da rotação dos esquemas internalizados, produzindo progressivamente o colapso da estrutura que domina no cinema. Assim também a cinética da câmera, seguindo um padrão estrutural, interfere para a quebra da continuidade narrativa e evidencia o simulacro. O plano móvel é marcado ritmicamente e de maneira perceptível com os temas musicais compostos antes do início da filmagem, formando entre si uma trama de impulsos e pausas.

A passagem entre a cozinha e a sala de jantar é conduzida e emoldurada por trechos de Memorial, em uma pregnância que se impõe à percepção. Marcando efetivamente nessa transição uma região intervalar, um lugar estranho e denso, porém, vazio. Em implicações reflexivas, a interação entre as 
várias molduras de um imaginário e o abstrato de cada um, é aqui ativada pela música em seus espasmos contínuos. A música com uma potência dramatúrgica fascinante como representação da sociedade, de distinção social, marca de classe fundamental, enfatiza o aspecto irônico e satírico através da mediatização entre o erudito e o popular; como contradição entre substância, ligada à constituição imanente e a sociedade - de que nasceu e em que está - e, por inclusão intencional do que é culinariamente gostoso, mas que somente se revelará e se "degustará" no todo. Em sua forma estética, o espaço da forma musical realiza tendências estruturantes da sociedade.

A cena de Georgina e seu amante fugindo, diretamente extraída de Masaccio em "A Expulsão de Adão e Eva" que carrega da temática cristã o desejo como a origem do pecado - o pecado original - atinge com outro momento da mesma música que domina o filme o desespero máximo de uma experiência repugnante.

Situação limiar, transição que nos fala de fronteira, de interstício, passagem em que a solidez está ameaçada. Através de sua invasão espacial, dos ecos assimilados pela memória cultural, a perturbadora adequação da música às imagens, com os temas desdobrados ao máximo, vinculando situações mais que personagens, concorre de modo determinante para a composição da obra.

Se com essa música, fazendo ressoar um mesmo motivo e cadência, a aflição muda e a tensão é mantida; o tema do encontro dos amantes - Fish Beach - vai do simples acompanhamento à ambigüidade da referência, visto já ter sido duplamente utilizado: em Drowning by Numbers e em The Falls. A música cria vínculo através do referencial. Na instrumentação musical, o timbre da pontuação vai se alterando a jogar em contraponto com o que é visto na tela em uma série de paralelismo e rotações.

O requinte é extremo, pois além do jogo com as imagens visuais e com as referências anteriores, o timbre é a cor própria do som. Acentuando-se que timbre também é conhecido em música como um motivo melódico já existente, que o compositor utiliza para criar um novo texto - como é próprio do proce- 
dimento de Nyman (o compositor musical) e, na transposição, de Greenaway (o compositor da cena). Também ao ser utilizado como motivo condutor entre filmes, por sua reiteração na idéia temática quase metonímica, alude ao objeto emoldurando uma outra situação e subordinando a idéia de uma morte no fim do jogo. Na condensação e deslocamento, a metáfora: o amante que "caiu na rede" e que morrerá asfixiado, abatido por sufocação, como um peixe, ou um pato.

A memória atua como estoque de impulsos e narração dos mesmos, despindo-se da moldura romântica e do sentimentalismo; na variação da repetição, vai mudando o seu conteúdo. A questão não é preencher o espaço tempo ordinário com coisas novas mas, muito mais, um novo agenciamento de espaço e de tempo sem dar tempo de digerir tudo. Na profusão dos detaIhes, intensificam-se as molduras concretas e culturais onde a coerência, na produção como objeto de sentido, é dependente de certos pressupostos tanto do artista como da audiência.

Com a decupagem destacando a imposição de uma certa "leitura" e o aspecto quaternário da estrutura musical permitindo o corte como síncope, às vezes a expressão viva e rítmica dos gestos e vozes é sublinhada pela música exercendo o papel de contraponto narrativo; em outras, proporciona ressonâncias que induzem a níveis perceptivos próximos ao onírico desperto. Como na seqüência do encontro dos amantes na despensa ao som da música Memorial, enquanto paralelamente é enfatizada a destreza do gesto ao cortar os vegetais com o som correspondente preenchendo as circunstâncias visualizadas, ouve-se a música em correlação com o som do corte. Ambos são, ao mesmo tempo, de uma mesma condição sensorial e homóloga, constituindo motivos rítmicos propriamente poéticos que, além de seu valor direto, afetam a audiência por sua própria consistência sensorial.

A duração, os movimentos, constitui um corte do espaçotempo criando um tempo particular. Tão pulsional que continua pelo corpo mesmo quando pára. Regulação da temporalidade em um estágio especial do passado atualizado. Na repetição, propriedade comum tanto da música quanto da poética, o ritmo forma um todo estruturado na sucessão de estímulos que 
se evocam mutuamente; estabelecendo-se, em confluência e bifurcações entre os planos. Em relações de apropriação, segundo os modos de assimilação, cria um hiato sobre as combinações do nosso imaginário e das fendas que se abrem em fragmentos fugidios.

As apresentações dos cardápios diferenciando o dia sinalizam o ato e remetem à divisão de uma ópera, aos letreiros do primeiro cinema, aos cartazes no teatro, bem como à tabuleta do teatro elisabetano com a utilização da palavra escrita para evocar um quadro. Mostrando ao mesmo tempo para o espectador o próprio instrumento gerador de seu devaneio. Ao pontuar que se assiste e se participa de uma realização encenada, dirige os sentidos à percepção da escrita autoral para além dos reflexos condicionados, derivados do cotidiano adestramento; apontando que o restaurante, como o cinema, é onde o gosto burguês se alimenta: o que ingerimos nos mantém, é alimento.

$\mathrm{Na}$ ambigüidade entre a modernidade encarnada no trabaIho coletivo e a produção especializada como arte, o cozinheiro, o cineasta, articulador e manipulador regendo a preparação do alimento a ser consumido. Salientando, ao evidenciar os artifícios reprocessando os elementos, que se há uma internalização das regras do cinema dominante, dos esquemas perceptivos - se este já é digerível e palatável - com a diferenciação na mescla dos ingredientes procura possibilidades de singularização oferecendo um outro deguste.

A auto-referência é uma das formas paradigmáticas da reflexão estética de Greenaway. No processo de concepção podemos entender o cinema como uma poética, a arte como techn; jogando com uma série de motivos situacionais, de ecos, reiterações como a multiplicação de imagens sobre um jogo de espelhos, de criações, de emergências, satura o fio narrativo em uma série de interferências. Sinais diferentes em várias freqüências que funcionam como ruídos, estabelecendo relações que determinam diferenciais entre forma e conteúdo e que provocam uma inquietude levando à reflexão.

Ao envolver e jogar com a nossa capacidade de participação e interferência, salienta ainda o paradoxo da centralização, do nosso olhar como enquadramento, da manipulação ilusória, da 
aparência. No fato de estarmos sentados assistindo o discurso do encenador, do nosso modelo ainda preso a forma renascentista; a idéia de que se olha de frente para ver uma determinada imagem, prescindindo que tem um observador participante, que o objeto está sendo observado, como a tela de Frans Hals sobre a sala de jantar e sobre nós. Dentro de um conjunto de possibilidades, porém, os diversos atratores quebram o esquema da perspectiva central da visão renascentista, derivando, fragmentando, relativizando a cena. Um procedimento que também se manifesta através do espaço cênico.

Como situação caleidoscópica onde o sentido mais importante é o discernimento, possibilita o pensar a partir de um campo de imanência labiríntico. As estratégias deliberadamente transparentes, que induzem o audiente a identificar as configurações, destacam regimes de representação produzidos por dispositivos ao longo da história; e que se manifestam através de determinados paradigmas, ampliando suas ressonâncias em uma multiplicidade da qual, paradoxalmente, muito se perde quando se tenta apreender através da linguagem puramente analítica. Ao evidenciar esta produção, a composição cria uma outra relação que emerge na articulação das molduras que transgride qualquer realismo. Transfigurando-o na medida em que o virtualiza e rompendo com o poder de verdade até mesmo através da literalização das metáforas processadas no jogo paródico.

As configurações se apresentam reiteradas em diferentes contextos, em circulariedade sígnica, apontando as camadas ambíguas de citações, de referências. Como na alegoria do poder masculino de Spica e seus comparsas que como emblema do grupo imitam, em seus uniformes extravagantes e ousados, os elementos de uma guilda mercantilista retratados pela imensa tela que domina a sala de jantar. Em cena, o quadro reproduz o "Banquete dos Oficiais da Milícia Cívica de São Jorge, em Harleem", tela de Frans Hals de 1616, em que os oficiais retratados, num tempo-espaço suspenso, em torno de uma mesa para a ceia observam a cena. Para além de uma situação de ilustração, ao conter traços daquele período é uma situação de extrato. O espectador real do interior do quadro é representado 
do ponto de vista exterior. Nessa construção, como desdobramento e intermezzo, a posição da audiência é virada do avesso, pois não só de dentro da tela presencia o acontecimento, mas interage.

Na rima entre molduras, o contorno compartilhado permite diálogos intertextuais. Ao olhar o quadro de fora dessas molduras, a audiência - que somos nós - é posta na mira pois, invertendo a imagem do outro, encontra-se na mesma posição que a audiência interior da tela ao fundo; no sentido dado pela simultaneidade e em justaposição com a temporalidade do acontecimento dramático, a imobilidade do quadro, a mobilidade da imagem e a mobilização da audiência - como personagem em relação, enquanto emblema e alegoria. Em explicação simplista, por substituir ou aludir a nossa presença, qual espelho de Narciso, os outros também somos e estão em nós.

$\mathrm{Na}$ justaposição a noção do poder e da quebra da representação é inquestionável. Se o padrão fornece o vínculo, o conteúdo da organização, para a conservação da identidade do grupo; o paradigma das maneiras à mesa é intensificado através do contraste. O ladrão se empanturra com sua corte, o prazer percebido é o da devoração, não há deguste; os talheres, como extensão dos membros, precisam os gestos e como instrumentos servem também para o ataque.

Spica é apresentado como um tirânico glutão embriagado pelo próprio discurso orgíaco que tangencia o obsceno - mas que praticamente não come, se alimentando de palavras que na fala, falam por ele - comida e sexo em sua voracidade são comparáveis. Na cisão entre a palavra e a coisa, o corpóreo tem relação dinâmica com o consumismo. Estabelece-se assim um jogo extremamente dinâmico com os sentidos do audiente, salientado através de arquétipos, de estereótipos inseridos em múltiplas situações (palavras, gestos, imagens sonoras e visuais) onde nada pode ser compreendido em si, ou só o que parece ser, mas sempre em relação.

Uma metáfora gastronômica sobre o canibalismo, sobre o que se come, o que se consome, o que serve de alimento - uma relação desarmônica a expressar a condição humana, em sua fixação oral e anal. Assim também, às vezes, os motivos 
em detalhes são evidenciados na composição; pois no cinema, conforme propagado por Adorno, "o elemento emoldurado é sempre o tempero mais forte do conjunto".

A ênfase na entonação - indicativa da atitude do locutor, de seu lugar e gestus social - reforça o padrão de conduta geral, política e privada dentro do grupo. A boca é um instrumento do intelecto. As observações culinárias apontam às idiossincrasias do paladar; tendo no erotismo um condimento necessário e natural. Dessa forma enquanto o ladrão disfarçado de burguês, que em referência direta à animalidade revela-se um primata do instinto, com seu sotaque portuário dirige-se ao cozinheiro de maneira infantilizada; este último em seu linguajar cerimoniosamente elisabetano, ao enfatizar o Mr. Spica (com um forte acento francês) remete ao tratamento impessoal em uma instância tipicamente inglesa que é a Câmara dos Comuns.

Mas mesmo na tipificação das personagens surgem outras relações estabelecidas com a inserção de outros signos que poluem o enquadramento tipológico. Georgina e Michael são apresentados como tendo o paladar apurado, entretanto ela fuma compulsivamente e ele lê enquanto come. O aparente refinamento dela contrasta com a ignorância intelectual: na cena do depósito, ela vendo os livros que o amante catalogava pergunta impressionada se ele havia lido todos.

Já em uma interpretação pessimista que critica o conhecimento teórico como uma crença que se converte em magia animista, a atitude do solitário amante, como ávido leitor de História, é a reprodução indefinida de certo tipo de necessidade emergente com a forma da indústria cultural, como consumidor de uma mercadoria sofisticada: catalogador da Revolução Francesa. Além do armazenamento de informações ser um recurso de poder e controle social, é um gesto que se inscreve em um certo tipo de consumo, de organização industrial de consumo. E que, ao repetir o mesmo, revela o fetichismo, a banalização, a alienação tão presente onde o objeto domina o próprio criador que se coisifica, no jogo contraditório entre os elementos postos em interação.

Continuando a leitura dialética, ao jogar com o ver como 
ato selvagem do ladrão versus o ler cultural do amante, apresenta uma terrível visão do processo constitutivo do indivíduo como sujeito, partindo da inadequação do mundo dramatizado. Por entre a situação que se estabelece, no decurso do seu próprio desmascaramento e através da inversão de valores, faz parte de um universo real: o adestramento como internalização das regras em uma cultura autoritária, onde não se pode afastar ilesamente do obtuso padrão estabelecido. A presença do obsceno, do orgânico e do escatológico aponta limites da sociabilidade e o barbarismo. Por sua vez, cada maneira de compreensão é aprofundada por tênues molduras que se ataviam em reverberações que a nós se revelam e através do repertório e da percepção nos limitam, nos enquadram, nos encaixam, emoldurando culturalmente.

Na pulsão de apelo pela representação há uma formalização consciente da ritualização. Assim, da religião judaico-cristã a organização a partir da culpa e da punição permeia como um aparato, pois a relação entre opressor e oprimido, antes de ser transcendental, é sobretudo algo que está distribuído num feixe de instâncias, em campos heterogêneos, campos de poder, de saber, sobretudo campos mistos onde a mescla saber-poder está sempre funcionando.

Ao mesmo tempo, nas personagens contrapostas, para além de uma síntese dialética podemos problematizar a técnica de produção da subjetividade, um dispositivo que se articula em regimes discursivos: ao ladrão totalitário, o amante, advindo do esclarecimento filosófico - o sujeito historicamente constituído. No sentido nietzscheano o que está em jogo não é uma vontade de verdade, não é uma vontade de dominação, não é uma vontade de saber, é uma vontade de criação pensada de uma maneira transgressiva a partir do primado do acontecimento, da irrupção, do novo, da diferença, da descontinuidade, como um movimento que escapa de si mesmo.

Para tanto, na mise en film o acontecimento é essencialmente apresentado pela sua faceta exterior, as personagens - na articulação, volume e impostação da voz em uma dicção teatralizada e na gesticulação estudada como matiz constante - se dirigem ao outro; tanto quando o ladrão jura matar ou 
Georgina se confessa ao amante morto como em expurgação do seu pecado. Também no dramatismo da morte violenta do amante em mãos do ladrão, através da absorção das páginas de livros como um corpo estranho e indigesto, e que jaz de olhos abertos com o livro The Terror em seu peito. Ao mesmo tempo em que podemos perceber o sinal de que a lei repousa sobre a força bárbara e física do dominante - como um emblema de um corpo vivente testemunha atuante do presente em movimento e não de um passado desaparecido - se percebe a ironia incisiva parodiando a tragédia: o terror e a piedade.

Já na cena em que Georgina se confessa, ao mesmo tempo em que se assinala a impossibilidade de acesso à interioridade alheia evidencia-se o voyeurismo implícito em toda representação. Na confissão ela se vira e olha diretamente para a câmera, como um ponto morto, e representa que não está sendo observada. Ao mesmo tempo nos insta como testemunhas por nos encontrarmos presentes, espreitando a cena e participando desse ritual.

Na denegação da identificação como voyeurs e no reconhecimento da circularidade do olhar, percebemos sobremaneira nesse instante que nosso olhar está incluído na cena. Em ambos os momentos, no jogo de reflexos e correspondências com que nos olhamos ao olhar constatamos essa passagem. Tal como com a tela de Hals, também nessa imagem se dá o reconhecimento do voyeurismo implícito em toda ação de causa-efeito. Essa passagem é reforçada pela fala do cozinheiro na cena seguinte: "vi o que você me deixou ver", com ela retrucando que precisava de uma testemunha para se certificar que aconteceu, que era verdade. Conforme ele descreve percebemos que são as cenas que nos foram deixadas ver ou inferimos - presentes em nossa imaginação.

Realizado o ato sacrificial e o da confissão como um gesto de fé, o mito cristão do canibalismo - consumado na comunhão através de uma incorporação simbólica - é igualmente concretizado em cena. Com a vingança também convertida em ato ritual, a última seqüência acentua as características operística quando, comandados por Georgina e lembrando a procissão de Corpus Christi, os vitimados adentram em cortejo a sala 
de jantar com o corpo do amante.

A solenidade artificial é ritmada ao som de Memorial que somente aqui se desenvolverá em sua íntegra. No banquete alusivo à Santa Ceia transgressivamente é reinscrito o sinal da mutilação sobre a carne. Depois de Spica ter bebido o vinho servido por Roy, a primeira vítima mostrada, Georgina retira o sudário e expõe o corpo do amante. Mas, como em um agenciamento da natureza em transformação - assinalada pela morte de Deus e do sujeito - não ocorre nenhuma transubstanciação mística: o marido gargantua é intimado por Georgina - que detém a arma, o poder e portanto a voz, calando o falastrão - a comer a carne do amante: "Vamos Albert... coma!" Na pausa o grito lancinante da voz, como intérprete e instrumento da música, atinge uma grandiloqüência que marca todo o final.

A solidão, a impossibilidade de comunicação e o absurdo associam-se com grande força ao contexto frente ao qual nada é sagrado; ou o é, se cremos que toda memória é também uma ressurreição. Com trágico humor, em sua ironia mordaz e impactante, destrói as expectativas de uma conclusão através da transcendência do homem sobre o mundo decaído. Obscenidade de situações limite que explodem a realidade.

Fecham-se as cortinas, créditos finais. A música continua... Penetrante, cria uma presença que filtra e organiza a experiência: como signos postos em cena aproximou-se a linguagem do cinema das formas do pensamento desestruturando e abalando qualquer crença.

Quod non sapis, quod non vidis,

Animosa firmat fides

Praeter rerum ordinem

"O que não experimentas pelo sabor e o que não vês, a fé corajosa afirma além da ordem das coisas"

Tomás de Aquino 


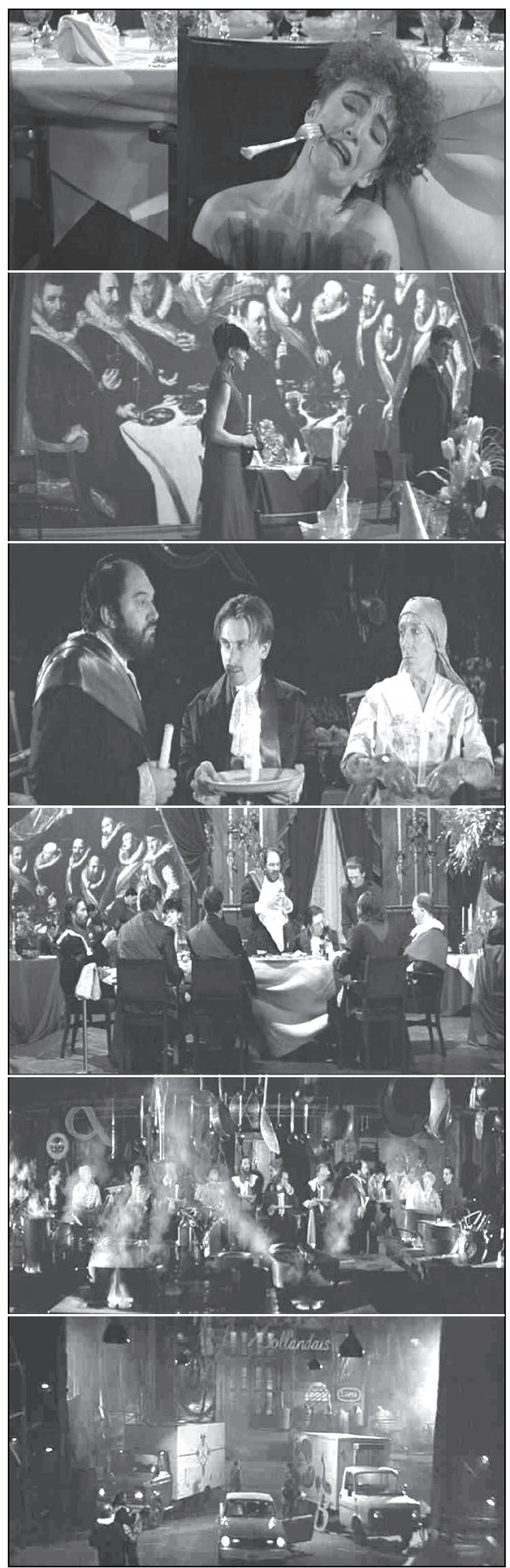

Imagens: http://petergreenaway.co.uk 


\section{Referências}

ADORNO, T. et al. Textos escolhido. 2. ed. São Paulo: Abril Cultural, 1983. BOSSEUR, J. Y. Le Sonore et le Visuel: intersections musique/arts plastiques aujord'hui. Paris: DisVoir 1995.

GREENAWAY, P. The Cook, the Thief, his Wife \& her Lover. Paris: Disvoir, 1991.

KERMAN, J. A pera como drama. Tradução Eduardo F. Alves, Rio de Janeiro: Zahar, 1990.

NYMAN, M. Experimental music, CAGE and beyond. New York: Schirmer Books, 1981.

PAZ, O. Marcel Duchamp ou o Castelo da Pureza. Tradução Sebastião Uchôa Leite. São Paulo: Perspectiva, 1977.

PILARD, P. (Org.): Peter Greenaway. France: Ed. DisVoir, 1987.

ROUBINE, J.J. A Linguagem da encenao teatral. Tradução Yan Michalski. Rio de Janeiro: Zahar, 1998.

RUWET, N. Langage, musique, posie. Paris: Éditions du Seuil, 1972.

SINZIG, P. Dicionrio musical: pelo mundo do som. Rio de Janeiro: Kosmos, 1947.

TRAGTenBerG, L. Msica de cena. São Paulo: Perspectiva, 1999.

\section{CLELIA MELLO}

professora da Faculdade de Artes Visuais da Universidade Federal de Goiás. Possui doutorado em Ciências da Comunicação (ECA-USP) e pós-doutorado pelo Programa de Estudos Pós-graduados em Comunicação e Semiótica (PUC-SP). Tem experiência na área de Artes com ênfase em Poéticas Imagem-Som. Email: clelia_mello@yahoo.com 